\title{
Complications in the treatment of carpal tunnel syndrome
}

\section{Philip Henkin, M.D., and Allan H. Friedman, M.D.}

\section{Division of Neurosurgery, Duke University Medical Center, Durham, North Carolina}

Complications may result from every facet of the management of carpal tunnel syndrome. The authors review the common errors in diagnosis, nonoperative management, and operative treatment, with emphasis on prevention and resolution of complications. In general, surgeons can minimize complications by taking a thorough patient history, performing a comprehensive physical examination, and possessing a precise knowledge of the appropriate anatomy. Endoscopic techniques appear to offer some advantage over conventional open techniques with regard to the patient's postoperative incision pain, preservation of grip strength, and time to return to work; however, these advantages may be potentially negated by the risk of injury to neurovascular structures and tendons.

Key Words * carpal tunnel syndrome * carpal tunnel release * transverse carpal ligament

Release of the transverse carpal ligament (TCL) has become the most commonly performed peripheral nerve operation. The widespread popularity of the procedure is largely a consequence of the ubiquitous nature of the syndrome, the pervasive awareness of the syndrome by clinicians and patients, and the excellent response in most patients to surgical treatment. Since surgical decompression of the TCL was first performed by Learmonth in 1933[49] many authors have reported a high success rate performing the procedure in several large series of patients.[2,12,13,23,37,44,72,82] Concomitant with the increased volume of carpal tunnel releases (CTRs), complications have become more prevalent. MacDonald, et al.,[57] reported 34 complications in 22 patients (12\%) undergoing 186 operations for carpal tunnel syndrome (CTS). With the advent of endoscopic CTR (ECTR), the potential for neurovascular and tendon injuries has increased, especially when the surgeon performing the procedure is at the beginning of the learning curve.[79] Furthermore, the practice of many academic hand surgeons includes more patients managed for complications of CTR than patients presenting with the initial symptoms of the syndrome.[97] Based on a 1987 survey of members of the American Society of Hand, this experience is typical for many hand surgeons. The survey revealed that $70 \%$ of the 467 respondents performed one to five reoperations per year for CTS and 16\% performed more than six reoperations per year.[14] Although few surgical procedures are associated with such low morbidity rates, complications from CTR surgery can still be quite disabling to the patient. We will facilitate this review by arbitrarily dividing the complications into four catagories: 1) errors in diagnosis; 2) errors in nonoperative management; 3) complications in open CTR (OCTR) surgical treatment; and 4) complications in ECTR treatment.

\section{ERRORS IN DIAGNOSIS}

Although the most commonly cited complications in carpal tunnel decompression are incomplete release 
of the TCL and injury to the palmar cutaneous branch of the median nerve, $[11,47,54,57]$ the incomplete or incorrect diagnosis of CTS is truly the most prevalent management error. The physician's failure to recognize comorbidities will result in incomplete resolution of the patient's symptoms after surgery. Likewise, the physician's inability to differentiate CTS from the many maladies that may mimic its symptoms will result in minimal improvement because of inappropriate treatment. A thorough history and physical examination of the entire upper extremity and cervical spine is essential for the diagnosis of CTS. The classic patient presentation for CTS is a middle-aged woman with the gradual onset, over months, of nocturnal paresthesias in the median nerve distribution, which later progresses to pain, numbness, and clumsiness in the hands. In a review of 1016 patients, nocturnal symptoms, considered by some clinicians to be a sine qua non of the diagnosis, were found to be the second most common symptom complex ( $71 \%$ of patients) after paresthesias in the median nerve distribution (100\% of patients).[91] Physical findings in CTS are surprisingly mild compared with the magnitude of the patient's complaints. With the frequent paucity of other physical findings, provocative tests can be useful diagnostic adjuvants.

The classic provocative tests, Phalen's sign and Tinel's sign, are subject to subtle variations in test technique, which probably account for the large discrepancies in reported prevalence. The reported prevalence of Phalen's sign ranges from 10\%[75] to 88\%[31] and that of Tinel's sign ranges from 8\%[75] to $69 \%$.[31] A review by Slater and Bynum[88] of 3707 patients reported by six authors, $[26,31,40,73,75,78]$ yields an average prevalence of $45 \%$ for positive Tinel's sign and $52 \%$ for positive Phalen's sign in patients with CTS. From the same review, 361 control subjects without CTS exhibited an average prevalence for positive Tinel's sign of 35\% and 19\% for positive Phalen's sign. $[27,29,46,85]$ Because the sensitivity and specificity of the two classic signs are less than optimal, investigators have attempted to develop other noninvasive tests.

Threshold tests such as vibrometry and Semmes-Weinstein monofilaments and innervation-density tests such as two-point discrimination have shown some potential as noninvasive screening tests for CTS. Szabo, et al.,[92] demonstrated the increased sensitivity of threshold tests over two-point discrimination for detecting early sensory changes in nerve compression. Spindler and Dellon[89] compared the sensitivity of sensibility testing (vibratory stimuli, two-point discrimination) with nerve conduction studies. Results from their study of 74 symptomatic hands indicated that nerve conduction studies were more sensitive (81\%) than sensibility testing (66\%) in confirming the diagnosis of CTS, but the combination of the two studies was more sensitive than either test alone (92\%). Although noninvasive threshold tests such as vibrometry and Semmes-Weinstein monofilaments demonstrated promise in the early detection of nerve compression in limited clinical trials,[92] larger clinical screening trials provided contrary evidence that nerve conduction studies were much more sensitive to the early sensory changes in CTS. $[89,99]$

Electrodiagnostic studies may not be necessary in all cases, but they are clearly indicated when the diagnosis is in doubt. The principle purpose of nerve conduction studies is to provide evidence to support the diagnosis, quantify the severity of the diagnosis, exclude other diagnoses, and provide a baseline for patients with persistent symptoms. Many surgeons are reluctant to operate in the face of a normal electromyographic study, even though false-negative rates have been reported to be in the range of $8 \%$ [34] to 13\%.[55] An even greater risk of excessive reliance on nerve conduction studies is the performance of CTR in normal patients. Nathan, et al.,[68] demonstrated that the false-positive rate for nerve conduction studies may be as high as $6 \%$ in a study in which they reported positive nerve conduction studies in 13 of 213 asymptomatic patients. 
Many systemic diseases are associated with CTS and treatment of these underlying diseases may resolve the CTS-like symptoms. Thickening of the tenosynovium occurs with rheumatoid arthritis,[65] deposition of gouty tophi,[33,70] deposition of amyloid,[22] or tuberculosis.[42] Acromegaly produces actual thickening of the TCL in addition to hypertrophy of the synovium. Synovial engorgement may result from physiological states that cause retention of fluids such as pregnancy,[30,61] hypothyroidism,[76] and congestive heart failure.[90] Renal dialysis probably causes synovial edema due to increased intravascular flow.[81] Peripheral neuropathies associated with diabetes mellitus, chronic renal failure, and alcoholism alter peripheral nerves so that they are more susceptible to the compressive effects of CTS.

Other more proximal neuropathies may mimic and even coexist with CTS. Because CTS can produce referred pain to the elbow, shoulder, and neck, it may clinically resemble a C-5 or C-6 radiculopathy. Thoracic outlet syndrome, idiopathic brachial plexitis (Parsonage-Turner syndrome), pronator syndrome, and median nerve constriction at the ligament of Struthers may mimic some of the symptoms of CTS. Median neuropathies can occur as part of a more widespread peripheral neuropathy such as mononeuritis multiplex. In elderly patients, CTS may manifest predominantly as hand clumsiness and loss of dexterity. Several disorders of the central nervous system may produce some symptoms similar to CTS. Mass lesions of the foramen magnum, parietal infarctions, cervical spondylosis, and syringomyelia may all produce hand numbness, clumsiness, and slowness of movement.

The "double-crush" syndrome was the term coined by Upton and McComas[96] to describe the simultaneous compression of a single nerve by two compressive lesions. According to this theory, the proximal lesion lessens the ability of that nerve to withstand a more distal compression by impairing axonal flow. This scenario is well represented by tandem cervical radiculopathy secondary to spondylosis coexisting in a patient with CTS. The results of most studies investigating this phenomenon demonstrate that these patients benefit from CTR surgery but the success rate is lower than in patients with isolated CTS.[10,15]

\section{ERRORS IN NONOPERATIVE MANAGEMENT}

Injection of the carpal tunnel with corticosteroid agents and wrist splinting are the principle components of nonoperative treatment. Although most clinicians would affirm that corticosteroid injection into the carpal canal produces symptomatic relief, its effectiveness is often short-lived. Green[32] injected 122 wrists and attained good results (more than $50 \%$ relief of symptoms) in $81 \%$ of patients. In most patients, symptoms began to recur at an average of 3.3 months, but in only $46 \%$ were the symptoms severe enough to require surgery. In a prospective study, Gelberman, et al.,[25] treated 50 patients by using a single injection of a steroid agent and splinting, and they achieved complete resolution of symptoms in $76 \%$ of their patients at 6 weeks. Unfortunately, the percentage of patients free of symptoms had declined to $22 \%$ at 18 months. Using a strict definition of success as "complete resolution of symptoms," Weiss, et al.,[98] reported a success rate of only $13 \%$ at an average follow-up time of 11 months in 76 wrists treated with splinting and steroid injection. In light of the transient response to steroid injection and splinting, its most successful application is in the setting of pregnancy. Ekman-Ordeberg, et al.,[16] reported complete resolution of CTS symptoms in $80 \%$ of 56 pregnant women treated by splinting of the wrist at night. Only four of 56 patients required surgery because of persistent symptoms.

Direct intrafascicular injection of corticosteroid agents can cause widespread axonal and myelin degeneration, as demonstrated by Mackinnon, et al.[58] Both median and ulnar nerve injuries resulting 
from corticosteroid injection have been reported.[53,63,94] Direct injection of the median nerve may produce persistent dysesthesias for weeks or months. Direct injection of flexor tendons may cause tendon rupture, especially in patients suffering from rheumatoid arthritis. Accumulation of the vehicle in which the steroid agents are suspended may produce a synovitis and thus may need to be removed by microsurgical technique during an OCTR procedure.

Use of the proper injection technique will generally prevent intraneural injection. The injection technique described by Green[32] is recommended. A 25-gauge needle is placed $1 \mathrm{~cm}$ proximal to the distal flexion crease, ulnar to the palmaris longus tendon or in line with the ring finger. The needle is introduced at a 30 š angle to the skin and advanced just past the TCL. If paresthesias are elicited, the needle is withdrawn and angled closer to the skin before the second advance.

\section{COMPLICATIONS IN OPEN SURGICAL TREATMENT}

Most surgical complications in OCTR surgery result from inadequate or inappropriately placed skin incisions. Although there is considerable variability in the incisions chosen by particular surgeons, three general principles govern the design of the incision. First, the incision should allow adequate exposure under direct vision to section the TCL completely throughout its length. Blind cuts of the ligament will obviously place neurovascular structures in jeopardy. Second, an incision placed too radially will predispose to injury of the distal median nerve branches and one centered far toward the ulna will predispose to injury of the ulnar neurovascular bundle. Third, the incision should not cross the flexion crease at a right angle because a hypertrophic scar will often result. The transverse incision has been condemned because of the risk of injury to the palmar cutaneous branch of the median nerve.[45] In addition, the transverse incision predisposes to blind distal cuts of the TCL and subsequent injury to the digital nerves,[82] superficial palmer arch, median nerve, and flexor tendons.

Several studies cite incomplete sectioning of the TCL as the most common complication in OCTR.[47,57] MacDonald, et al.,[57] reported 12 cases of incomplete release of the ligament, constituting $35 \%$ of the total 34 complications found in 186 patients. Langloh and Linscheid[47] found incomplete resection of the TCL in 21 of 34 wrists investigated for persistent symptoms following surgery. Most of the 21 partially intact ligaments remained in continuity distally, most likely resulting from an attempt to avoid the the superficial palmar arch and the digital nerves. Other authors have stressed the importance of releasing the distal forearm fascia a few centimeters proximal to the wrist crease.[19]

Injury to the palmar cutaneous branch (PCB) of the median nerve is probably the second most commonly cited complication in OCTR surgery.[47,54,57] Transection of the nerve with subsequent neuroma formation was recognized in 1972 by Carroll and Green.[6] When transection of the PCB with subsequent neuroma formation occurs, the two recommended treatment options are to sever the PCB at its origin from the median nerve[6,54] or to bury the neuroma in the forearm muscles.[97] Taleisnik[93] investigated the anatomy of the nerve in a study of 12 cadavers and concluded that the best incision to avoid the terminal fibers of the PCB of the median nerve is a curved longitudinal one located on the ulnar side of the axis of the ring finger ray. Engber and Gmeiner[17] encountered two patients with neuromas in the hypothenar area following CTR surgery and subsequently performed a study of 21 cadavers to define the PCB of the ulnar nerve more clearly. Based on their anatomical findings, they concluded that the optimal incision was one in line with the axis of the ring finger. Martin, et al.,[60] conducted another cadaveric study of the cutaneous innervation of the palm in response to the continued occurrence of 
painful incisions following OCTR; presumably the pain was caused by injury to cutaneous nerves with subsequent neuroma formation. They demonstrated that such an incision centered on the axis of the ring finger resulted in injury to ulnar-based cutaneous nerves in 16 of 25 cadavers and injury to median-based cutaneous nerves in three of 25 cadavers. Thus, even though an incision based on the axis of the ring finger may lessen the incidence of palmer cutaneous nerve injury, there is no true "internervous plane" that will completely avoid all cutaneous palmer branches, whether of median or ulnar origin. The findings of Martin, et al., intimate that shorter incisions with subcutaneous release of the ligament under direct vision or ECTR may be the only methods of decreasing incision pain from neuromas of cutaneous nerves.

Besides injury to the cutaneous branches of the ulnar nerve, other reported ulnar nerve injuries include laceration of the nerve in Guyon's canal,[20] transection of the deep motor branch of the ulnar nerve just distal to the hook of the hamate in the midpalmar space,[95] and division of the sensory ramus communicans between the ulnar and median nerves.[62] The ulnar nerve and artery lie radial to the hook of the hamate and volar to the ulnar aspect of the TCL in 15\% of individuals,[97] which predisposes them to injury during inadvertent release of Guyon's canal.

Injuries to the superficial palmar arch,[57] the ramus communicans between the ulnar and median nerves,[62] and the common digital nerve to the adjacent long and ring fingers,[82] have all been reported. Their anatomical proximity to the distal edge of the flexor retinaculum is described in detail in the surgical anatomy section of the paper by Friedman in this issue.

Severance of the thenar motor branch (TMB) of the median nerve results in thenar atrophy and loss of opposition. Lilly and Magnell[52] reported good results in delayed repair, as late as 14 months, following initially unrecognized TMB injuries. Poisel[74] and Lanz[48] described several anatomical variants that are particularly susceptible to injury. In a study of 100 cadavers, Poisel found that the TMB becomes recurrent and exits from the median nerve distal to the TCL in $46 \%$ of cases. He documented an early ramification of the TMB under the ligament in $31 \%$ of cases and through the ligament in $23 \%$. The transligamentous variant is probably more vulnerable because transection of the radial aspect of the ligament can produce TMB injury. Lanz[48] delineated the median nerve anatomy in 246 hands explored at operation and reported additional anatomical variations that may predispose to injury, including accessory branches of the median nerve at the distal carpal tunnel and origination of the TMB from the ulnar side of the median nerve.

Long-term persistent pain is a major determinant of the success or failure of the OCTR. The complication of long-term persistent pain may arise from any of the following causes: hypertrophic skin scarring, intra- and perineural scarring, adherence of the nerve to the skin, subcutaneous tender nerve secondary to superficial position, adhesions between flexor tendons and the median nerve, pillar pain at the thenar and hypothenar eminences, and reflex sympathetic dystrophy (RSD).

Hypertrophic scars are often the result of an incision that transverses the flexion crease at a right angle. If a painful hypertrophic scar should occur despite all attempts at prevention, scar revision should be performed. Although the skin of the palmer side of the wrist is thin and immobile, a Z-plasty after scar revision is usually possible and is the easiest remedy.

Intra- and perineural scarring sometimes produces dysesthesias, pain, and hypersensitivity. Neurolysis is seldom a successful remedy and can potentially produce further scarring as well as direct mechanical injury to nerve fascicles during extensive dissection. In fact, internal neurolysis at the initial CTR 
procedure has never demonstrated any benefit over CTR without internal neurolysis;[26,59] thus, most hand surgeons would agree that internal neurolysis at the inital surgery is seldom indicated. Proper hemostasis is important to prevent perineural scarring. If intra- and perineural scarring should develop despite the surgeon's best efforts to prevent it, the hypersensitivity and dysesthesias may respond to coverage of the nerve with a fat graft or abductor flap.[97]

Superficial position of the median nerve and adherence of the nerve to the skin are usually consequences of an improper skin incision directly over the nerve, rather than toward the ulna. Splinting the wrist in a slightly dorsiflexed position for the first 3 to 5 postoperative days may lessen the likelihood of superficial nerve position. Three common methods of insulating the nerve from the skin surface include: rotation of a hypothenar fat-pad flap; rotation of local muscle pedicle flaps, such as the pronator quadratus and abductor digiti minimi; and Z-plasty with underlying temporary silicone sheeting to prevent scar adherence.[97]

Tendon adhesions may result from poor hemostasis during conventional OCTR surgery or from bleeding associated with tenosynovectomy. Resection of the synovium is usually indicated only in cases of extremely bulky synovium, such as those associated with rheumatoid arthritis, because of the propensity of tenosynovectomy to cause bleeding and scar formation with subsequent adhesions between tendons or between tendons and the median nerve.[97] Surgical drains may also diminish the incidence of adhesions but have been associated with a higher rate of infection. If postoperative splints are used, removal of splints by postoperative Day 3 lessens the risk of adhesions by allowing early mobilization of the tendons. Physical therapy with range-of-motion exercises and dynamic splinting rather than tenolysis surgery is the best treatment.[97]

Because the median nerve carries approximately $70 \%$ of the sympathetic nerve supply to the hand, RSD may result from carpel tunnel decompression. MacDonald, et al.,[57] reported four cases of RSD among 34 complications. Additionally, they described three stages of RSD in which the first stage is characterized by swelling, hyperesthesia, skin that is warm and dry, and persistent pain aggravated by movement. Progression to the second stage includes proximal spread of pain and edema, shiny skin that is cool and pale with atrophic changes, and joint stiffness. The third stage manifests as progressive atrophy with joint contractures and intractable pain. Early recognition and treatment are essential in the management of RSD. Initial therapy includes a 1-week course of oral corticosteroid and Stelazine medications accompanied by physical therapy.[97] This treatment usually resolves the syndrome, obviating the need for stellate ganglion blocks.

Pillar pain is an ill-defined, aching discomfort in the thenar and hypothenar eminences aggravated by gripping. Its etiology remains obscure but many attribute it to transection of the sensory nerve fibers supplying the palmaris brevis fascia and the resulting neuroma formation.[18] Other possible mechanisms include widening of the carpal arch and realignment of the carpal bones.[24] Seradge and Seradge[84] attributed persistent hypothenar eminence pain in five of 500 patients to an abnormal piso-triquetral joint, which resulted from an intercarpal alignment change after ligament release.

Deep wound infection was reported in 17 patients at the Mayo Clinic. Statistically significant risk factors for the infections included intraoperative instillation of steroid agents into the carpal canal, flexor tendon synovectomy, prolonged operative time, and the use of a surgical drain.[36] Treatment consists largely of surgical debridement with a primary closure or delayed primary closure when wound conditions permit. A suboptimal result occurred in seven of 17 patients at final follow-up evaluation. Superficial infection 
rates are generally low compared with other surgical procedures. Gainer and Nugent[23] documented 26 "minor" infections in 430 operations. Phalen[73] reported one superficial infection in 212 cases.

Bowstringing of the flexor tendons is a rare, readily reparable complication in OCTR, cited in two of 34 complications by MacDonald, et al.[57] Bowstringing can usually be prevented by immobilizing the wrist in slight extension for 3 to 5 postoperative days. If bowstringing should occur, it can be easily corrected by reconstructing the TCL. Jakab, et al.,[39] sectioned the ligament, reconstructed it with a lengthened ligament, and demonstrated resolution of CTS symptoms in $93 \%$ of patients who experienced no loss of grip strength.

Immediate postoperative loss of grip strength occurs in all patients and persists in up to one-third of patients undergoing OCTR surgery. Kluge, et al.,[43] evaluated grip strength at a minimum of 10 months after surgery in 66 patients ( 89 hands) by subjective patient self-assesment. Grip strength was judged to be normal in only $47 \%$. Gellman, et al.,[28] measured the time course of recovery of grip and pinch strength using a dynamometer. Grip strength was expressed as a percentage of the preoperative ipsilateral grip strength. Grip strength was 28\% of the preoperative level by 3 weeks; $73 \%$ by 6 weeks, and returned to the preoperative level by 3 months. Loss of grip strength, scar tenderness, and persistent pillar pain are late sequelae of the OCTR procedure and have provided much of the impetus to switch to the alternative of ECTR.

\section{COMPLICATIONS IN ENDOSCOPIC TREATMENT}

Endoscopic CTR techniques were first reported in 1989.[9,71] Since their introduction, rapid adoption of these techniques has transpired. In contradistinction to the application of endoscopic techniques to other surgical procedures, such as abdominal surgeries, ECTR has not decreased operative expense, increased operative efficiency, or improved intraoperative visualization (compared with conventional OCTR).[5,35] Despite these shortcomings, ECTR has many proponents who cite the potential benefits of faster patient recovery time, less incision pain, and improved grip strength recuperation.[1,5,7,8] Two large, prospective, randomized, multicenter, clinical trials comparing OCTR and ECTR methods emphasize the aforementioned potential benefits of ECTR.[1,5]

Agee, et al.,[1] reported a randomized, prospective, multicenter study of 147 hands (65 OCTR patients vs. 82 ECTR patients) in which the median time to return to work was 21 days shorter in the ECTR group than the OCTR group. The best predictors of return to work were incision tenderness and return of grip strength. There were three complications in the ECTR group: one incomplete release of the ligament and two transient ulnar nerve neuropraxias. There were four complications in the OCTR group: two wound dehiscences, one bowstringing of the flexor tendons, and one injury to the deep motor branch of the ulnar nerve. In the other study, Brown, et al.,[5] reported a randomized, prospective, multicenter study of 160 hands ( 82 OCTR patients vs. 78 ECTR patients) in which the median return to work time was 14 days shorter in the ECTR group than the OCTR group. Persistent incision tenderness was present in $61 \%$ of OCTR patients versus $36 \%$ of ECTR patients at 12 weeks. There were no complications in the OCTR group and four complications in the ECTR group: one partial transection of the superficial palmer arch, one digital nerve contusion, one ulnar nerve neuropraxia, and one wound hematoma. Despite the faster recovery time in their study, Brown, et al., expressed the concern that "the greater rate of complications indicates that intraoperative safety must be improved before ECTR is performed on a widespread basis." In addition to these two studies, several other studies comparing OCTR and ECTR procedures have been published.[1,3,5,18,35,38,83,87] Table 1 summarizes some of the pertinent 
findings. The faster return to work, decreased incidence of incision pain, and increased preservation of grip strength during the first 2 to 3 postoperative months associated with ECTR have been affirmed by several authors. $[1,4,18,83]$ In general, these potential benefits of ECTR predominate in the 1st several postoperative weeks but diminish significantly beyond this time period.

\begin{tabular}{|c|c|c|c|c|}
\hline & COMPA & ARISON & $\begin{array}{c}\text { TABLE } 1 \\
\text { OF RESULTS AND COMPLCATIONS IN PA } \\
\text { OCTR AND ECTR PROCEDURES }\end{array}$ & TIENTS UNDERGONG \\
\hline $\begin{array}{l}\text { Authors } \\
\text { \& Year }\end{array}$ & $\begin{array}{l}\text { No. of } \\
\text { OCTRs }\end{array}$ & $\begin{array}{l}\text { No. of } \\
\text { ECTRs }\end{array}$ & Resuls & Complications \\
\hline $\begin{array}{l}\text { Agee, et al. } \\
1992\end{array}$ & 65 & 82 & $\begin{array}{l}\text { ECTR: be tter grip \& pinch strength } \\
3 \text { mks postop; less scar tender- } \\
\text { ness at } 9 \text { mks }\end{array}$ & $\begin{array}{l}\text { OCTR: deep motor tranch ulnar } \\
\text { ner ve (1), boustringing of flexor } \\
\text { tendon (1), wound dehisoenoe } \\
\text { (2); ECTR: incom plete TCL } \\
\text { resection (1), transient ulnar } \\
\text { neuropraxia. (2), persistent } \\
\text { sym ptoms (1) }\end{array}$ \\
\hline $\begin{array}{l}\text { Erown, et al., } \\
1993\end{array}$ & 82 & 78 & $\begin{array}{l}\text { ECTR: quicker return to work, im- } \\
\text { proved pinch strength, less scar } \\
\text { tendemess, more com plications; } \\
\text { no difference in patient satisfac- } \\
\text { ton or relief of num tness \& } \\
\text { paresthesias }\end{array}$ & $\begin{array}{l}\text { OCTR: no com plications; ECTR: } \\
\text { superficial palmar arch transec- } \\
\text { ton (1), hematoma (1), digital } \\
\text { nerve contusion (1), ulnar } \\
\text { neuropraxia (1) }\end{array}$ \\
\hline Bande, et al., & 58 & 44 & $\begin{array}{l}\text { postop questionnaire; no significant } \\
\text { difference in return to mork time or } \\
\text { relief of sum ptoms }\end{array}$ & OCTR: none; ECTR: none \\
\hline $\begin{array}{l}\text { Erdmann, et } \\
\text { al., } 1994\end{array}$ & 52 & 53 & $\begin{array}{l}\text { ECTR: quicker return of grip \& pinch } \\
\text { strength; return to mork time } \\
\text { (ECTR } 14 \text { days, OCTR } 34 \text { days) }\end{array}$ & $\begin{array}{l}\text { OCTR: hypertrophic scar (5), scar } \\
\text { tethering (1), wound infection (1); } \\
\text { ECTR: : lnar ner we paresthesia } \\
\text { (1) inomm dete TC resecion }\end{array}$ \\
\hline $\begin{array}{l}\text { \$off \& \& \&lar, } \\
1994\end{array}$ & 20 & 20 & $\begin{array}{l}\text { no difference in return to work time, } \\
\text { relief of paresthesias, or grip } \\
\text { strength }\end{array}$ & $\begin{array}{l}\text { Octh: none; EcTh: digital } \\
\text { nerve neuropraxa (1) }\end{array}$ \\
\hline $\begin{array}{l}\text { Hallock \& } \\
\text { Lutz, } 1995\end{array}$ & 71 & 66 & $\begin{array}{l}\text { no statistical difference in return to } \\
\text { work time, trend to earlier retum } \\
\text { with ECTR; no statistical differ- } \\
\text { ence in scar length or rate of } \\
\text { complications }\end{array}$ & $\begin{array}{l}\text { OCTR: none; ECTR: digital } \\
\text { nerve neuropraxia (1) }\end{array}$ \\
\hline $\begin{array}{l}\text { Sennivald \& } \\
\text { Benedetti, } \\
1995\end{array}$ & 22 & 25 & $\begin{array}{l}\text { ECTR: superior grip strength at } 3 \\
\text { mos; return of function (ECTR } \\
24 \text { days, OCTR } 42 \text { days) }\end{array}$ & $\begin{array}{l}\text { OCTR: hypertrophic scar (1), } \\
\text { RSD (1); E CTR: neuropraxia } \\
\text { 3rd common digital nerve }\end{array}$ \\
\hline $\begin{array}{l}\text { Jacobsen \& } \\
\text { Rahme, } 1996\end{array}$ & 16 & 16 & $\begin{array}{l}\text { no difference in return to work time } \\
\text { or improvement in median nerwe } \\
\text { electrophysiological values }\end{array}$ & $\begin{array}{l}\text { OCTR: none; ECTR: digital } \\
\text { nerve neuropraxa (3) }\end{array}$ \\
\hline
\end{tabular}

Although the decreased palmar tenderness, better preservation of grip strength, and earlier return to work associated with ECTR are very noteworthy, these advantages may be negated by the risk of neurovascular and tendon injury. Many surgeons remain skeptical about the safety and reliability of ECTR. According to recent studies, the overall complication rate is in the range of 1 to $2 \%$ in experienced hands for both ECTR and OCTR surgery. Despite a comparable complication incidence, the quality of the complications is vastly different.[4] A complete laceration of the median or ulnar nerve is a devastating injury. These types of injuries are exceedingly rare in OCTR but have been reported not infrequently in ECTR. Endoscopic carpel tunnel release is a technically demanding procedure in which there is a steep learning curve. Rowland and Kleinert[79] reported a 17\% complication rate for 12 hand surgeons who were learning the technique on cadaveric specimens. Injury to the following structures has 
been reported with ECTR: median nerve,[5,21,66,77] ulnar nerve,[67] digital nerve,[5,64] superficial palmar arch,[5,66] wound hematoma,[5] flexor tendon injury,[35] RSD,[86] and incidental release of Guyon's canal.[56] Two of these injuries are often the direct result of endoscopic cannula placement. The radial digital nerve of the fourth finger can be injured at the distal port, $[5,39]$ and the ulnar neurovascular bundle can be injured at the proximal port by inadvertent entry into Guyon's canal.[50,67] Because of this potential for neurovascular and tendon injury, most endoscopic surgeons agree that if the transverse striations of the TCL cannot be visualized along its entire length, the endoscopic procedure should be converted to an open one.

Incomplete ligament release ranges from $5 \%$ to as high as 50\% in cadaveric studies.[50,51] Lee, et al.,[50] reported three types of incomplete release: 1) release of Guyon's canal, 2) incomplete distal ligament release, and 3) incomplete central (superficial) ligament release. The most common difficulties were penetration of the ligament with the cannula and inability to distinguish the proximal and distal ends of the ligament. Schwartz, et al.,[80] demonstrated incomplete release of the TCL in four of 13 cadavers and incomplete sectioning of the fascia connecting the thenar and hypothenar muscles in four more of the 13 cadavers in which an ECTR procedure had been performed by a surgeon trained to use the Agee 3M Inside Job device (3M Corp., St. Paul, MN). The true incidence of incomplete release of the ligament in noncadaveric studies is difficult to determine. Kelly, et al.,[41] reported five incomplete releases in 83 hands in which the Chow technique of ECTR had been used. Only two incomplete releases were reported in the 384 hands undergoing ECTR in Table 1.

In the final analysis, the optimal CTR technique would be one which incorporates the decreased incision tenderness, increased preservation of grip strength, and earlier return to work provided by ECTR with the lower incidence of serious neurovascular and tendon injuries found in OCTR. A technique that might fit this description is that of OCTR using a short (approximately $2 \mathrm{~cm}$ ) incision, as reported by Hallock and Lutz[35] and Nathan, et al.[69] In contrast to the two comparative studies by Brown, et al.,[5] and Agee, et al.,[1] Hallock and Lutz[35] reported no statistical difference in scar length, scar tenderness, rate of complications, or length of time before return to work in a prospective series of 71 patients undergoing OCTR surgery through an average $2.1-\mathrm{cm}$ incision versus 66 patients in whom a two-portal technique was used. There were no iatrogenic injuries in the OCTR group and one possible digital nerve injury in the ECTR group. The average incision made by Hallock and Lutz was $2.1 \mathrm{~cm}$ compared with a 3.5- to 4.5-cm incision made by Brown, et al. Hallock and Lutz's data support their contention that the minimal-incision OCTR technique can achieve the same low incidence of incision tenderness and fast recovery as ECTR, without the potential complications. The benefits of increased recovery of function and a short average return-to-work interval of 17 days were demonstrated in another study incorporating a short-incision OCTR technique with intensive physical therapy.[69]

\section{References}

1. Agee JM, McCarroll HR Jr, Tortosa RD, et al: Endoscopic release of the carpal tunnel: a randomized prospective multicenter study. J Hand Surg (Am) 17:987-995, 1992

2. Ariyan S, Watson HK: The palmar approach for the visualization and release of the carpal tunnel. An analysis of 429 cases. Plast Reconst Surg 60:539-547, 1977

3. Bande S, De Smet L, Fabry G: The results of carpal tunnel release: open versus endoscopic technique. J Hand Surg (Br) 19:14-17, 1994 
4. Bozentka DJ, Osterman AL: Complications of endoscopic carapal tunnel release. Hand Clin 11:91-95, 1995

5. Brown RA, Gelberman RH, Seiler JG III, et al: Carpal tunnel release: a prospective, randomized assessment of open and endoscopic methods. J Bone Joint Surg (Am) 75:1265-1275, 1993

6. Carroll RE, Green DP: The significance of the palmar cutaneous nerve at the wrist. Clin Orthop 83:24-28, 1972

7. Chow JC: The Chow technique of endoscopic release of the carpal ligament for carpal tunnel syndrome: four years of clinical results. Arthroscopy 9:301-314, 1993

8. Chow JC: Endoscopic release of the carpal ligament for carpal tunnel syndrome: 22-month clinical result. Arthroscopy 6:288-296, 1990

9. Chow JC: Endoscopic release of the carpal ligament: a new technique for carpal tunnel syndrome. Arthroscopy 5:19-24, 1989

10. Clayburgh RH, Beckenbaugh RD, Dobyns JH: Carpal tunnel release in patients with diffuse peripheral neuropathy. J Hand Surg (Am) 12:380-383, 1987

11. Conolly WB: Pitfalls in carpal tunnel decompression. Aust NZ J Surg 48:421-425, 1978

12. Cseuz KA, Thomas JE, Lambert EH, et al: Long-term results of operation for carpal tunnel syndrome. Mayo Clin Proc 41:232-241, 1966

13. Doyle JR, Carroll RE: The carpal tunnel syndrome. A review of 100 patients treated surgically. Calif Med 108:263-267, 1968

14. Duncan KH, Lewis RC Jr, Foreman KA, et al: Treatment of carpal tunnel syndrome by members of the American Society for Surgery of the Hand: results of a questionnaire. J Hand Surg (Am) 12:384-391, 1987

15. Eason SY, Belsole RJ, Greene TL: Carpal tunnel release: analysis of suboptimal results. J Hand Surg (Br) 10:365-369, 1985

16. Ekman-Ordeberg G, Salgeback S, Ordeberg G: Carpal tunnel syndrome in pregnancy. A prospective study. Acta Obstet Gynecol Scan 66:233-235, 1987

17. Engber WD, Gmeiner JG: Palmar cutaneous branch of the ulnar nerve. J Hand Surg (Am) 5:26-29, 1980

18. Erdmann MW: Endoscopic carpal tunnel decompression. J Hand Surg (Br) 19:5-13, 1994

19. Eversmann WW Jr: Complications of compression of entrapment neuropathies, in Boswick JA (ed): Complications in Hand Surgery. Philadelphia: WB Saunders, 1986, pp 99-115

20. Favero KJ, Gropper PT: Ulner nerve laceration--a complication of carpal tunnel decompression: case report and review of the literature. J Hand Surg (Br) 12:239-241, 1987

21. Feinstein, PA: Endoscopic carpal tunnel release in a community-based series. J Hand Surg (Am) 18:451-454, 1993 
22. Fenves AZ, Emmet M, White M, et al: Carpal tunnel syndrome with cystic bone lesions secondary to amyloidosis in chronic hemodialysis patients. Am J Kidney Dis 7:130-134, 1986

23. Gainer JV Jr, Nugent GR: Carpal tunnel syndrome: report of 430 operations. South Med J 70:325-328, 1977

24. Gartsman GM, Kovach JC, Crouch CC, et al: Carpal arch alteration after carpal tunnel release. J Hand Surg (Am) 11:372-374, 1986

25. Gelberman RH, Aronson D, Weisman MH: Carpal-tunnel syndrome. Results of a prospective trial of steroid injection and splinting. J Bone Joint Surg (Br) 62:1181-1184, 1980

26. Gelberman RH, Pfeffer GB, Galbraith RT, et al: Results of treatment of severe carpal-tunnel syndrome without internal neurolysis of the median nerve. J Bone Joint Surg (Am) 69:896-903, 1987

27. Gellman H, Gelberman RH, Tan AM, et al: Carpal tunnel syndrome. An evaluation of the provocative diagnostic tests. J Bone Joint Surg (Am) 68:735-737, 1986

28. Gellman H, Kan D, Gee V, et al: Analysis of pinch and grip strenth after carpal tunnel release. J Hand Surg (Am) 14:863-864, 1989

29. Golding DN, Rose DM, Selvarajah KL: Clincial tests for carpal tunnel syndrome: an evaluation. Br J Rheumatol 25:388-390, 1986

30. Gould JS, Wissinger HA: Carpal tunnel syndrome in pregnancy. South Med J 71:144-145, 1978

31. Graham RA: Carpal tunnel syndrome. A statistical analysis of 214 cases. Orthopedics 6:1283-1287, 1983

32. Green DP: Diagnostic and therapeutic value of carpal tunnel injection. J Hand Surg (Am) 9:850-854, 1984

33. Green EJ, Dilworth JH, Levitin PM: Tophaceous gout. An unusual cause of bilateral carpal tunnel syndrome. JAMA 237:2747-2748, 1977

34. Grundburg AB: Carpal tunnel decompression in spite of normal electromyography. J Hand Surg 8:348-349, 1983

35. Hallock GG, Lutz DA: Prospective comparison of minimal incision "open" and two-portal endoscopic carpal tunnel release. Plast Reconstr Surg 96:941-947, 1995

36. Hanssen AD, Amadio PC, DeSilva SP, et al: Deep postoperative wound infection after carpal tunnel release. J Hand Surg (Am) 14:869-873, 1989

37. Hybbinette $\mathrm{CH}$, Mannerfelt L: The carpal tunnel syndrome. A retrospective study of 400 operated patients. Acta Orthop Scand 46:610-620, 1975

38. Jacobsen MB, Rahme H: A prospective, randomized study with an independent observer comparing open carpal tunnel release with endoscopic carpal tunnel release. J Hand Surg (Br) 21:202-204, 1996

39. Jakab E, Ganos D, Cook FW: Transverse carpal ligament reconstruction in surgery for carpal tunnel 
syndrome: a new technique. J Hand Surg (Am) 16:202-206, 1991

40. Kasdan ML, Janes C: Carpal tunnel syndrome and vitamin B6. Plast Reconstr Surg 79:456-462, 1987

41. Kelly CP, Pulisetti D, Jamieson AM: Early experience with endoscopic carpal tunnel release. J Hand Surg (Br) 19:18-21, 1994

42. Klofkorn RW, Steigerwald JC: Carpal tunnel syndrome as the initial manifestation of tuberculosis. Am J Med 60:583-586, 1976

43. Kluge W, Simpson RG, Nicol AC: Late complications after open carpal tunnel decompression. J Hand Surg (Br) 21:205-207, 1996

44. Kulick MI, Gordillo G, Javidi T, et al: Long-term analysis of patients having surgical treatment for carpal tunnel syndrome. J Hand Surg (Am) 11:59-66, 1986

45. Kuschner SH, Brien WW, Johnson D, et al: Complications associated with carpal tunnel release. Orthop Rev 4:346-352, 1991

46. Kuschner SH, Ebramzadeh E, Johnson D, et al: Tinel's sign and Phalen's test in carpal tunnel syndrome. Orthopedics 15:1297-1302, 1992

47. Langloh ND, Linscheid RL: Recurrent and unrelieved carpal-tunnel syndrome. Clin Orthop 83:41-47, 1972

48. Lanz U: Anatomical variations of the median nerve in the carpal tunnel. J Hand Surg (Am) 1:44-53, 1977

49. Learmonth JR: The principle of decompression in the treatment of certain diseases of peripheral nerves. Surg Clin North Am 13:905-913, 1933

50. Lee DH, Masear VR, Meyer RD, et al: Endoscopic carpal tunnel release: a cadaveric study. J Hand Surg (Am) 17:1003-1008, 1992

51. Levy HJ, Soifer TB, Kleinbart FA, et al: Endoscopic carpal tunnel release: an anatomic study. Arthroscopy 9:1-4, 1993

52. Lilly CJ, Magnell TD: Severance of the thenar branch of the median nerve as a complication of carpal tunnel release. J Hand Surg (Am) 10:399-402, 1985

53. Linskey ME, Segal R: Median nerve injury from local steroid injection in carpal tunnel syndrome. Neurosurgery 26:512-515, 1990

54. Louis DS, Greene TL, Noellert RC: Complications of carpal tunnel surgery. J Neurosurg 62:352-356, 1985

55. Louis DS, Hankin FM: Symptomatic relief following carpal tunnel decompression with normal electroneuromyographic studies. Orthopedics 10:434-436, 1987

56. Luallin SR, Toby EB: Incidental Guyon's canal release during attempted endoscopic carpal tunnel release: an anatomical study and report of two cases. Arthroscopy 9:382-386, 1993 
57. MacDonald RI, Lichtman DM, Hanlon JJ, et al: Complications of surgical release for carpal tunnel syndrome. J Hand Surg (Am) 3:70-76, 1978

58. Mackinnon SE, Hudson AR, Gentilli F, et al: Peripheral nerve injection injury with steroid agents. Plast Reconstr Surg 69:482-490, 1982

59. Mackinnon SE, McCabe S, Murray JF, et al: Internal neurolysis fails to improve the results of primary carpal tunnel decompression. J Hand Surg (Am) 16:211-218, 1991

60. Martin CH, Seiler JG III, Lesesne JS: The cutaneous innervation of the palm: an anatomic study of the ulnar and median nerves. J Hand Surg (Am) 21:634-638, 1996

61. Massey EW: Carpal tunnel syndrome in pregnancy. Obstet Gynecol Surv 33:145-148, 1978

62. May JW Jr, Rosen H: Division of the sensory ramus communicans between the ulnar and median nerves: a complication following carpal tunnel release. A case report. J Bone Joint Surg (Am) 63:836-838, 1981

63. McConnell JR, Bush DC: Intraneural steroid injection as a complication in the management of carpal tunnel syndrome. A report of three cases. Clin Orthop 250:181-184, 1990

64. Menon J: Endoscopic carpal tunnel release: a single-portal technique. Contemp Orthop 26:109-115, 1993

65. Michaelis LS: Stenosis of the carpal tunnel, compression of median nerve and flexor tendon sheaths, combined and rheumatoid arthritis elsewhere. Proc Soc Med 43:414-417, 1950

66. Murphy RX Jr, Jennings JF, Wukich DK: Major neurovascular complications of endoscopic carpal tunnel release. J Hand Surg (Am) 9:114-118, 1994

67. Nath RK, Mackinnon SE, Weeks PM: Ulnar nerve transection as a complication of two-portal endoscopic carpal tunnel release: a case report. J Hand Surg (Am) 18:896-898, 1993

68. Nathan PA, Meadows KD, Doyle LS: The relationship of age and sex to sensory conduction of the median nerve at the carpal tunnel and association of slowed conduction with symptoms. Muscle Nerve 11:1149-1153, 1988

69. Nathan PA, Meadows KD, Keniston RC: Rehabilitation of carpal tunnel surgery patients using a short surgical incision and an early program of physical therapy. J Hand Surg (Am) 18:1044-1050, 1993

70. O'Hara LJ, Levin M: Carpal tunnel syndrome and gout. Arch Intern Med 120:180-184, 1967

71. Okutsu I, Ninomiya S, Takatori Y, et al: Endoscopic management of carpal tunnel syndrome. Arthroscopy 5:11-18, 1989

72. Phalen GS: The carpal-tunnel syndrome. Clinical evaluation of 598 hands. Clin Orthop 83:29-40, 1972

73. Phalen GS: The carpal tunnel syndrome. Seventeen years' experience in diagnosis and treatment of treatment of six hundred fifty-four hands. J Bone Joint Surg (Am) 48:211-228, 1966 
74. Poisel S: Ursprung und Verlauf des R. Muscularis des Nervus digitalis palmaris communis (N. medialis). Chir Praxis 18:471-474, 1974

75. Posch JL, Marcotte DR: Carpal tunnel syndrome. An analysis of 1,201 cases. Orthop Rev 5:25-35, 1976

76. Purnell DC, Daly DD, Lipscomb PR: Carpal tunnel syndrome associated with myxedema. Arch Intern Med 108:751-756, 1961

77. Resnick CT, Miller BW: Endoscopic carpal tunnel release using the subligamentous two-portal technique. Contemp Orthop 22:269-277, 1991

78. Rietz KA, Onne L: Analysis of sixty-five operated cases of carpal tunnel syndrome. Acta Chir Scand 133:443-447, 1967

79. Rowland EB, Kleinert JM: Endoscopic carpal-tunnel release in cadavers. An investigation of the results of twelve surgeons with this training model. J Bone Joint Surg (Am) 76:266-268, 1994

80. Schwartz JT, Waters PM, Simmons BP: Endoscopic carpal tunnel release: a cadaveric study. Arthroscopy 9:209-213, 1993

81. Semer NB, Goldberg NH, Cuono CB: Upper extremity entrapment neuropathy and tourniquet use in patients undergoing hemodialysis. J Hand Surg (Am) 14:897-900, 1989

82. Semple JC, Cargill AO: Carpal-tunnel syndrome. Results of surgical decompression. Lancet 1:918-919, 1969

83. Sennwald GR, Benedetti R: The value of one-portal endoscopic carpal tunnel release: a prospective randomized study. Knee Surg Sports Traumatol Arthroscopy 3:113-116, 1995

84. Seradge H, Seradge E: Piso-triquetral pain syndrome after carpal tunnel release. J Hand Surg (Am) 14:858-862, 1989

85. Seror P: Tinel's sign in the diagnosis of carpal tunnel syndrome. J Hand Surg (Br) 12:364-365, 1987 86. Shinya K, Lanzetta M, Conolly WB: Risk and complications in endoscopic carpal tunnel release. J Hand Surg (Br) 20:222-227, 1995

87. Skoff HD, Sklar R: Endoscopic median nerve decompression: early experience. Plast Reconstr Surg 94:691-694, 1994

88. Slater RR Jr, Bynum DK: Diagnosis and treatment of carpal tunnel syndrome. Orthop Rev 10:1095-1105, 1993

89. Spindler HA, Dellon AL: Nerve conduction studies and sensibility testing in carpal tunnel syndrome. J Hand Surg (Am) 7:260-263, 1982

90. Spinner RJ, Bachman JW, Amadio PC: The many faces of carpal tunnel syndrome. Mayo Clin Proc 64:829-836, 1989

91. Stevens JC, Sun S, Beard CM, et al: Carpal tunnel syndrome in Rochester, Minnesota, 1961 to 1980. Neurology 38:134-138, 1988 
92. Szabo RM, Gelberman RH, Williamson RV, et al: Vibratory sensory testing in acute peripheral nerve compression. J Hand Surg (Am) 9:104-109, 1984

93. Taleisnik J: The palmar cutaneous branch of the median nerve and the approach to the carpal tunnel. An anatomical study. J Bone Joint Surg (Am) 55:1212-1217, 1973

94. Tavares SP, Giddins GEB: Nerve injury following steroid injection for carpal tunnel syndrome. A report of two cases. J Hand Surg (Br) 21:208-209, 1996

95. Terrono AL, Belsky MR, Feldon PG, et al: Injury to the deep motor branch of the ulnar nerve during carpal tunnel release. J Hand Surg (Am) 18:1038-1040, 1993

96. Upton AR, McComas AJ: The double crush in nerve entrapment syndromes. Lancet 2:359-362, 1973

97. Urbaniak JR, Desai SS: Complications of nonoperative and operative treatment of carpal tunnel syndrome. Hand Clin 12:325-335, 1996

98. Weiss AP, Sachar K, Gendreau M: Conservative management of carpal tunnel syndrome: a reexamination of steroid injection and splinting. J Hand Surg (Am) 19:410-415, 1994

99. Werner RA, Franzblau A, Johnston E: Comparison of multiple frequency vibrometry testing and sensory nerve conduction measures in screening for carpal tunnel syndrome in an industrial setting. Am J Phys Med Rehab 74:101-106, 1995

Manuscript received June 3, 1997.

Accepted in final form June 10, 1997.

Address correspondence to: Allan H. Friedman, M.D., Division of Neurosurgery, Box 3807, Duke University Medical Center, Durham, North Carolina 27710. 